\title{
Volatile Fatty Acids from Lipid-Extracted Yeast Provide Additional Feedstock for Microbial Lipid Production
}

\author{
Gwon Woo Park ${ }^{1, * \mathbb{D}}$, Seongsoo Son ${ }^{2}$, Myounghoon Moon ${ }^{1}$, Subin Sin $^{1}$, Kyoungseon Min ${ }^{1}$, Jin-Suk Lee ${ }^{1}$ \\ and Ho Nam Chang ${ }^{3}$ \\ 1 Gwangju Bio/Energy R\&D Center, Korea Institute of Energy Research, Gwangju 61003, Korea; \\ mmoon@kier.re.kr (M.M.); tlstn120@kier.re.kr (S.S.); min4605@kier.re.kr (K.M.); bmjslee@kier.re.kr (J.-S.L.) \\ 2 KoBioLabs, Seoul 08826, Korea; sss0317@kobiolabs.com \\ 3 Department of Chemical and Biomolecular Engineering, Korea Institute of Advanced Science and Technology, \\ Daejeon 34141, Korea; hnchang@kaist.edu \\ * Correspondence: werwers@kier.re.kr
}

Citation: Park, G.W.; Son, S.; Moon, M.; Sin, S.; Min, K.; Lee, J.-S.; Chang, H.N. Volatile Fatty Acids from Lipid-Extracted Yeast Provide Additional Feedstock for Microbial Lipid Production. Catalysts 2021, 11, 1009. https://doi.org/10.3390/ catal11081009

Academic Editor: Diego Luna

Received: 23 July 2021

Accepted: 20 August 2021

Published: 21 August 2021

Publisher's Note: MDPI stays neutral with regard to jurisdictional claims in published maps and institutional affiliations.

\begin{abstract}
Microbial lipid production from oleaginous yeasts is a promising process for the sustainable development of the microbial biodiesel industry. However, the feedstock cost poses an economic problem for the production of microbial biodiesel. After lipid extraction, yeast biomass can be used as an organic source for microbial biodiesel production. In this study, volatile fatty acids (VFAs), produced via anaerobic digestion of a lipid-extracted yeast (LEY) residue, were utilized as a carbon source for the yeast Cryptococcus curvatus. The response surface methodology was used to determine the initial $\mathrm{pH}$ and inoculum volume for the optimal VFA production. The experimental result for VFA concentration was $4.51 \mathrm{~g} / \mathrm{L}$ at an initial $\mathrm{pH}$ of 9 and an inoculation $25 \%$. The optimization results from the response surface methodology showed that the maximal VFA concentration was $4.58 \mathrm{~g} / \mathrm{L}$ at an initial $\mathrm{pH}$ of 8.40 and an inoculation of $39.49 \%$. This study indicates that VFAs from LEY can be used as a carbon source for microbial biodiesel production, with the potential to significantly reduce feedstock costs.
\end{abstract}

Keywords: oleaginous yeast; volatile fatty acid; lipid-extracted yeast; response surface methodology; Cryptococcus curvatus

\section{Introduction}

The prospect of converting microbial lipids into biodiesel has attracted attention from many researchers because of the renewable potential of biofuel sources such as microalgae, fungi, and yeasts. Oleaginous yeasts are characterized by remarkable growth and show promise as a biofuel feedstock because of their high oil content (up to 67.5\%) [1-4]. However, biodiesel production from microbial lipids is much more expensive than from fossil fuels, because of the high costs of raw materials. The commodity feedstock cost accounts for the largest proportion of the total biofuel cost [5]. Considering a microalgal lipid content of 50\%, the per-liter production cost of biodiesel from algal oil varies from USD 1.08 to USD 1.34 [6,7]. Furthermore, yeasts such as Cryptococcus albidus [7-9], Cryptococcus curvatus [10-12], Yarrowia lipolytica [13,14], and Rhodosporidium toruloides [15,16], which can use low-cost volatile fatty acid (VFAs) materials (USD 20-100/ton) as carbon sources, can produce biodiesel at a cost of \$0.3-\$1.26/L [7]. VFAs are mainly composed of acetic acid, propionic acid, and butyric acid and are produced anaerobically from a variety of biomasses, including organic waste biomass, sludge, animal manure, microbe, plant, and animal biomass sources $[7,17,18]$. Hence, reducing the raw material-associated costs can economically impact biofuel production, with carbon source recycling serving as one of the major cost-reduction approaches. In addition, the maximum theoretical yield of microbial lipid yield is quite low (around $0.32 \mathrm{~g} / \mathrm{g}$ from glucose) and one-third carbon is released by $\mathrm{CO}_{2}$ producing Acetyl-CoA, which is the building block of fatty acids, during glucose 
metabolism [1]. Hence, it is necessary to increase carbon efficiency and lipid yield. A substantial amount of oleaginous yeast residue is generated after lipid extraction. Production of VFAs via anaerobic digestion of a lipid-extracted yeast (LEY) residue can potentially provide an additional carbon source. The recycling of VFAs via their utilization as carbon sources for oleaginous yeasts can lower biofuel production costs $[7,9,19]$. Although C. curvatus is a well-known high lipid-producing yeast, there are only a few studies on the production of VFAs from LEY. Therefore, in this study, a lipid-extracted C. curvatus cell residue was evaluated as a source for VFA production via anaerobic digestion by varying two parameters, the $\mathrm{pH}$ and the inoculation $[18,20-22]$.

\section{Results and Discussion}

\subsection{Preparation of a LEY Residue}

The cell mass and lipid content were $12.08 \mathrm{~g} / \mathrm{L}$ and $49.3 \%$, respectively, after $72 \mathrm{~h}$ of the cultivation of $C$. curvatus (Figure S1). The cell wall of the ellipsoid yeast cells (Figure 1A) was disrupted (Figure 1B) using an ultrasonic homogenizer in Folch solvent. After lipid extraction, the lipid content changed from $49.3 \%$ to $13.0 \%$ in the cell residue.
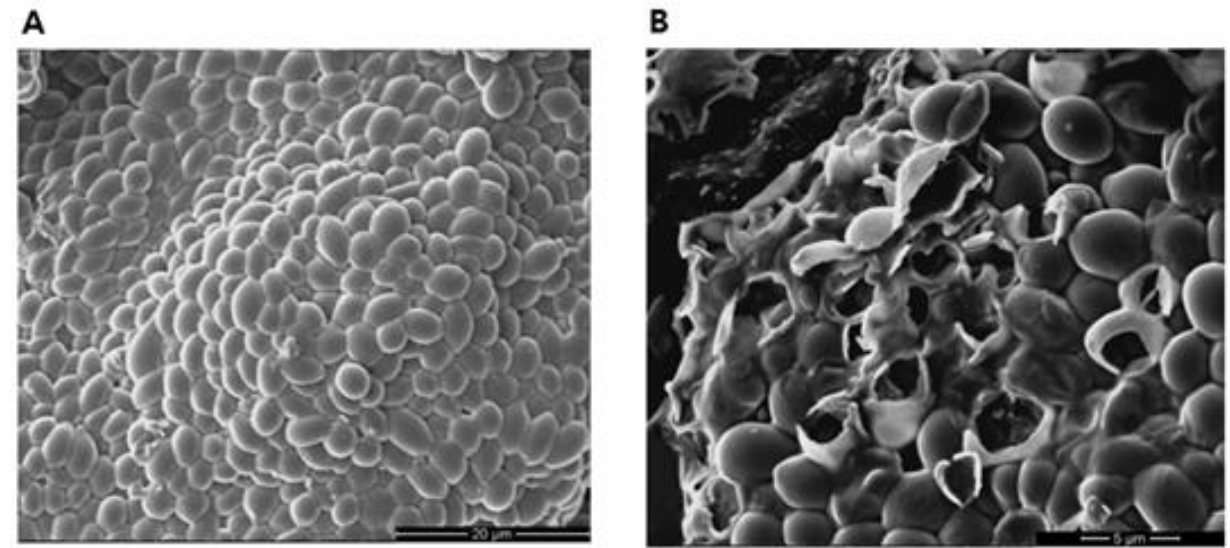

Figure 1. Scanning electron microscopy images of C. curvatus cells. (A) Before lipid extraction $(5000 \times)$ and (B) after lipid extraction $(10,000 \times)$.

\subsection{Application of Response Surface Methodology for the Optimization of VFA Production via Anaerobic Digestion}

The data from 11 trials conducted to assess VFA concentration responses using the CCD method are presented in Table 1. The experiments using the conditions represented by the center point, initially designated at $\mathrm{pH} 9.0$ and an inoculation ratio of $25 \%$, were repeated three times to estimate experimental errors.

Table 1. The central composite design of the variables and experimental VFA concentrations.

\begin{tabular}{cccc}
\hline Run & pH & $\begin{array}{c}\text { Inoculation } \\
(\%, \boldsymbol{v} / \boldsymbol{v})\end{array}$ & VFA Concentration $(\mathbf{g} / \mathrm{L})$ \\
\hline 1 & 6.5 & 5 & 3.10 \\
2 & 6.5 & 25 & 3.75 \\
3 & 6.5 & 45 & 3.41 \\
4 & 9.0 & 5 & 3.82 \\
$5^{*}$ & 9.0 & 25 & 4.20 \\
$6^{*}$ & 9.0 & 25 & 4.51 \\
$7^{*}$ & 9.0 & 25 & 4.27 \\
$8^{*}$ & 9.0 & 45 & 4.68 \\
10 & 11.5 & 5 & 1.38 \\
11 & 11.5 & 25 & 1.75 \\
\hline
\end{tabular}

* Center point was repeated three times. 
The independent variables, the initial $\mathrm{pH}\left(\mathrm{X}_{1}\right)$ and the inoculation $\left(\mathrm{X}_{2}\right)$, were linked to the VFA concentration by quadratic Equation (1):

$$
\text { VFA concentration }=4.37-0.86 \mathrm{X}_{1}+0.29 \mathrm{X}_{2}+0.067 \mathrm{X}_{1} \mathrm{X}_{2}-1.69 \mathrm{X}_{1}^{2}-0.19 \mathrm{X}_{2}^{2}
$$

The three-dimensional response surface plot of the quadratic model for VFA concentrations, with putative estimated optimums, is displayed in Figure 2. According to the response surface, the optimum condition fell within the boundaries of the design. Regression models that described the experimental data indicated correlations among the two independent parameters that affected the response, with an $R^{2}$ value of 0.97 for the VFA concentrations. This $R^{2}$ value highlights the adequate process model representation, as well as a good fit between the predicted and experimental results.
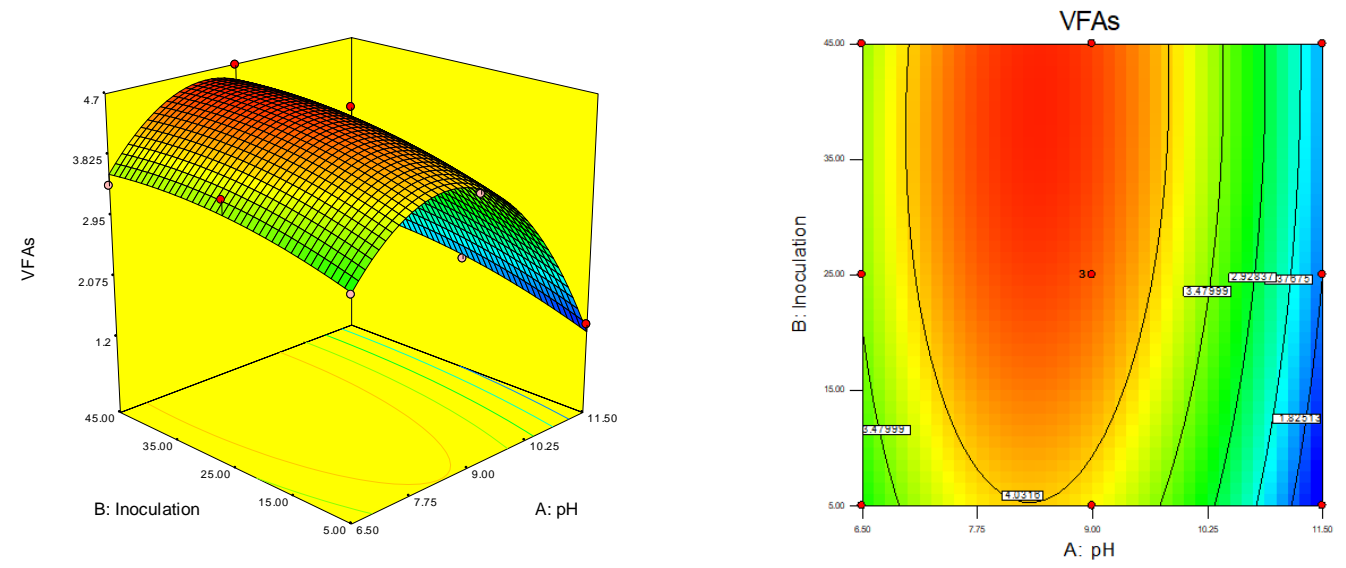

Figure 2. Two- and three-dimensional response surface plots of the quadratic model for VFA concentrations.

Table 2 shows the quadratic model analysis of variance (ANOVA) data for optimizing the VFA concentration during acidogenesis, involving two independent variables, as well as their interactions. Corresponding coefficients, with the statistical regression coefficients, were tested. The model confirmed using the given response surface was considered not significant with a lack of fit, but significant with an $\alpha$-level regression of $1 \%$. According to the significance determination of the independent variables, inoculation exhibited a trivial impact on the VFA concentration compared to initial $\mathrm{pH}$ from the ANOVA results. The maximum condition of VFA calculations, previously defined as the optimum conditions, were obtained by considering the partial derivatives as zero, based on the corresponding variables. The maximum VFA concentration was $4.58 \mathrm{~g} / \mathrm{L}$ at an initial $\mathrm{pH}$ of 8.40 and inoculation of $39.49 \%$. The estimates revealed that we could fit a quadratic model having an identical design boundary to the general environment of the VFA response surface. The model also exhibited a response plot that proceeded diagonally from the lower to the upper region with rounded ridges.

Defined response surfaces of the optimum response for unbounded polynomial models could be beyond the design boundary. These types of models extend the polynomial models to infinity. Hence, when predicting response surfaces, the models should include specific boundaries.

To validate the model, a point with an initial $\mathrm{pH}$ of 8.0 and inoculation of $10 \%$ was randomly selected for the experiment. In this trial, the experimental VFA concentration was $3.89 \mathrm{~g} / \mathrm{L}$, while the concentration after substitution in Equation (1) was $4.14 \mathrm{~g} / \mathrm{L}$. The error between the model and experimental data was $<10 \%$, confirming that the model equation could correctly fit the experimental data. 


\subsection{Recycling of the LEY Residue as a Feedstock for VFA Production}

The economic feasibility of industrial-scale biodiesel production is limited by the cost of raw materials, which account for more than $50 \%$ of the total production costs [23]. In our study, the LEY residue was used to produce VFAs by anaerobic digestion, and the yield was $0.458 \mathrm{~g}$ VFAs/g LEY. Furthermore, C. curvatus could efficiently utilize VFAs as a carbon source, yielding $0.62 \mathrm{~g}$ cells/g VFAs and $0.13 \mathrm{~g}$ lipids/g VFAs from our previous study [12]. Hence, $130 \mathrm{~g}$ of lipids was produced from $1 \mathrm{~kg}$ of VFAs by the oleaginous yeast (Figure 3A). Concurrently, $490 \mathrm{~g}$ of the cell residue (cell mass-lipids) was converted into VFAs via anaerobic digestion, yielding $224.4 \mathrm{~g}$ of VFAs (Figure 3B). Considering VFAs as an additional carbon source for yeast cultivation, the lipid production was increased by $22 \%$ through recycling (Figure 3C). Furthermore, if VFAs from LEY are considered as a carbon source for microbial lipid production, with persistent recycling, the total VFA production is calculated using an infinite geometric series, expressed as follows:

$$
\sum_{k=1}^{\infty} a r^{k-1}=\frac{a}{1-r}
$$

where $k$ is the recycling number, $a$ denotes the initial VFA mass, and $r$ represents the geometric ratio.

Table 2. Analysis of variance of the experimental VFA concentration data.

\begin{tabular}{cccc}
\hline \multirow{2}{*}{ Source } & $\begin{array}{c}\text { Degrees of } \\
\text { Freedom }\end{array}$ & Mean Square & $p$-Value \\
\cline { 3 - 4 } & 5 & 2.67 & 0.0001 \\
Model & 1 & 4.45 & 0.0001 \\
$\mathrm{X}_{1}$ & 1 & 0.51 & 0.0151 \\
$\mathrm{X}_{2}$ & 1 & 0.018 & 0.5243 \\
$\mathrm{X}_{1} \mathrm{X}_{2}$ & 1 & 7.26 & $<0.0001$ \\
$\mathrm{X}_{1}{ }^{2}$ & 1 & 0.091 & 0.1863 \\
$\mathrm{X}_{2}{ }_{2}$ & 5 & 0.039 & 0.3782 \\
Residual & 3 & 0.047 & \\
Lack of fit & 2 & 0.026 & \\
Pure error & 10 & & \\
Correlation total & $R^{2}=97.15 \%$ for VFA concentration \\
\hline
\end{tabular}

In the present study, the geometric ratio was calculated as follows:

Cell residue yield from VFAs $\times$ VFA yield from the residue $=0.490 \times 0.458=0.2244$

Based on Equations (2) and (3), unlimited recycling would increase the VFA concentration by $28.9 \%$ relative to that without recycling (Figure 3D). According to the mass balance of lipid production, $1 \mathrm{~kg}$ of the oleaginous yeast accounted for $493 \mathrm{~g}$ of lipids and $507 \mathrm{~g}$ of the cell residue. Hence, $299.4 \mathrm{~g}$ of VFAs could be produced from the recycling of the cell residue, with $38.9 \mathrm{~g}$ of converted lipids. Therefore, $1 \mathrm{~kg}$ of the oleaginous yeast would produce a maximum of $531.9 \mathrm{~g}$ of lipids. The yield of VFAs from LEY depends on the lipid extraction efficiency. However, we assumed that the lipid extraction efficiency was $100 \%$ and used the same yield data $(0.458 \mathrm{~g} / \mathrm{g})$ for the convenience of calculation in Figure 3 . 
A

$\begin{array}{ccc}\text { VFAs from } & \begin{array}{c}\text { Oleaginous } \\ \text { yeast cultivation } \\ 620 \mathrm{~g}-\text { cell } \\ 130 \mathrm{~g}-\text { lipid }\end{array} & \text { Lipid extraction } \\ 1 \mathrm{~kg} \text { - VFAs } & \text { Microbial Lipid }\end{array}$

B

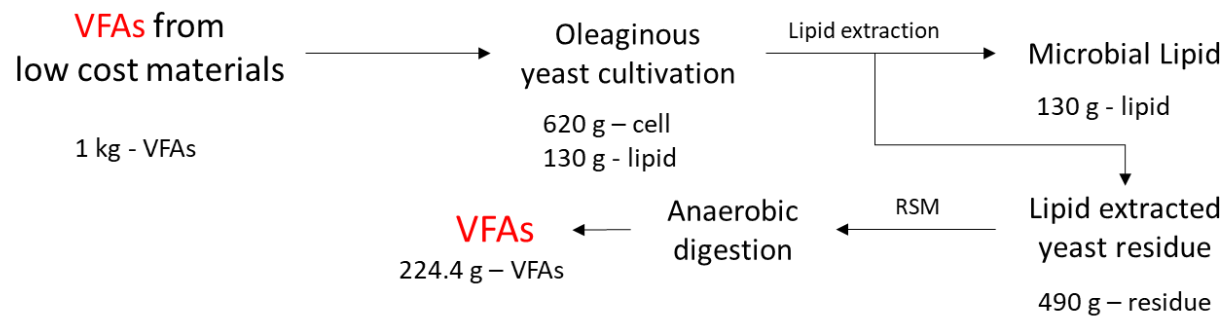

C

\begin{tabular}{|c|c|c|c|c|c|}
\hline \multirow{2}{*}{$\begin{array}{l}\text { VFAs from } \\
\text { low cost materials }\end{array}$} & \multirow{2}{*}{\multicolumn{3}{|c|}{ Oleaginous }} & Lipid extraction & \multirow{2}{*}{ Microbial Lipid } \\
\hline & & & & & \\
\hline \multirow{3}{*}{$224.4 \mathrm{~g}-\mathrm{VFAs}$} & & $139.1 \mathrm{~g}-$ & & & $29.2 \mathrm{~g}$ - lipid \\
\hline & & & & & \\
\hline & $\begin{array}{c}\text { VFAs } \\
50.3 \mathrm{~g}-\mathrm{VFAs}\end{array}$ & $\longleftarrow$ & $\begin{array}{l}\text { Anaerobic } \\
\text { digestion }\end{array}$ & & yeast residue \\
\hline
\end{tabular}

D VFAs from low cost materials

$1 \mathrm{~kg}$ - VFAs

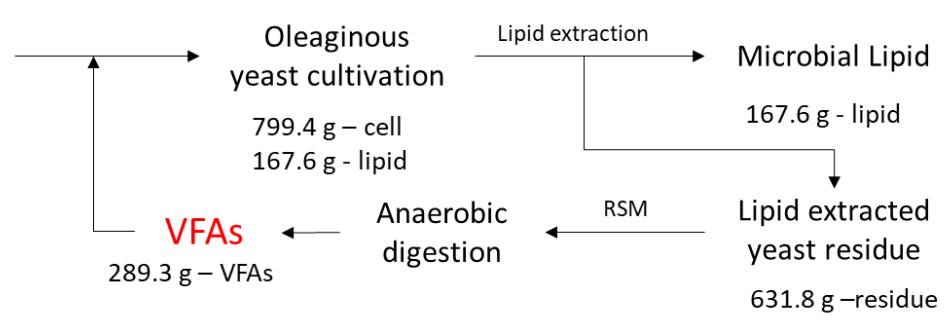

Figure 3. Mass balance of microbial lipid production from volatile fatty acids (VFAs) as low-cost materials and recycling of lipid-extracted yeast (LEY) residues. (A) Microbial lipid production from VFAs. (B) Microbial lipid production from VFAs and VFA production from the LEY residue. (C) Microbial lipid production from VFAs and additional VFAs by the one-time recycling of the LEY residue. (D) Microbial lipid production from VFAs and additional VFAs by the unlimited recycling of LEY residues.

\section{Materials and Methods}

\subsection{Yeast Cultivation}

C. curvatus (ATCC 20509, KCTC 7225) was obtained from the Korea Biological Resource Center (Daejeon, Republic of Korea). The strain was maintained by a monthly subculture on potato dextrose agar ( $2 \%$ dextrose, $0.4 \%$ potato infusion, and $1.5 \%$ agar). Seed culture was precultured for $25 \mathrm{~h}$ on YPD ( $2 \%$ dextrose, $2 \%$ peptone, $1 \%$ yeast extract) at $25{ }^{\circ} \mathrm{C}$. This culture was used for batch culture as an inoculum, and 10\% (v/v) inoculation was used. The batch culture was performed using a minimal medium ( $\mathrm{pH} 5.5$ ) in a $2.5 \mathrm{~L}$ fermenter containing the following per liter of distilled water: Glucose $20 \mathrm{~g}, \mathrm{NaNO}_{3} 1.2 \mathrm{~g}$, $\mathrm{KH}_{2} \mathrm{PO}_{4} 2.7 \mathrm{~g}, \mathrm{Na}_{2} \mathrm{HPO}_{4} 0.95 \mathrm{~g}, \mathrm{MgSO}_{4} 7 \mathrm{H}_{2} \mathrm{O} 0.2 \mathrm{~g}$, yeast extract $0.1 \mathrm{~g}$, and EDTA $0.1 \mathrm{~g}$. Supplemented with a $100 \times$ stock solution, which contained per liter: $\mathrm{CaCl}_{2} \cdot 2 \mathrm{H}_{2} \mathrm{O} 4 \mathrm{~g}$, $\mathrm{FeSO}_{4} \cdot 7 \mathrm{H}_{2} \mathrm{O} 0.55 \mathrm{~g}$, citric acid $\mathrm{H}_{2} \mathrm{O} 0.52 \mathrm{~g}$, $\mathrm{ZnSO}_{4} \cdot 7 \mathrm{H}_{2} \mathrm{O} 0.10 \mathrm{~g}, \mathrm{MnSO}_{4} \cdot \mathrm{H}_{2} \mathrm{O} 0.076 \mathrm{~g}$, and $100 \mu \mathrm{L} 18 \mathrm{M} \mathrm{H}_{2} \mathrm{SO}_{4}[12,24]$. Dry cell mass was determined by harvesting and transferring the culture broth to a pre-weighed tube after centrifugation. After washing twice with distilled water, the samples were dried at $85{ }^{\circ} \mathrm{C}$ overnight to achieve a constant weight. 


\subsection{Lipid Extraction of Yeast and Preparation LEY Residue Sample}

Lipid extraction was done with the Folch method [25] with minor modifications: $1.5 \mathrm{~g}$ of dry biomass (after lyophilization) was mixed with $30 \mathrm{~mL}$ Folch solvent $(2: 1 v / v$ of chloroform and methanol), with sonication for $30 \mathrm{~min}$ to break the cell wall. The mixture was then centrifuged at $8000 \mathrm{rpm}$ for $10 \mathrm{~min}$ and solvent discarded. Then, we washed twice with methanol to remove the remaining chloroform, washed with distilled water twice, and then lyophilized the sample.

\subsection{Anaerobic Digestion Operating Conditions}

The inoculum used was acquired from the Daejeon sewage disposal plant (total solids $=10.57 \mathrm{~g} / \mathrm{L}$, volatile solids $=4.45 \mathrm{~g} / \mathrm{L}$ ) and stored at $4{ }^{\circ} \mathrm{C}$. Then, $10 \mathrm{~g} / \mathrm{L}$ of yeast residue and different inoculation was used for each experiment. Modified RAMM medium $\left(1 \mathrm{~g} / \mathrm{L}\right.$ yeast extract, $0.27 \mathrm{~g} / \mathrm{L} \mathrm{KH}_{2} \mathrm{PO}_{4}, 0.35 \mathrm{~g} / \mathrm{L} \mathrm{K}_{2} \mathrm{HPO}_{4}, 0.53 \mathrm{~g} / \mathrm{L} \mathrm{NH} \mathrm{N}_{4} \mathrm{Cl}, 0.1 \mathrm{~g} / \mathrm{L}$ $\mathrm{MgCl} \cdot 6 \mathrm{H}_{2} \mathrm{O}, 0.075 \mathrm{~g} / \mathrm{L} \mathrm{CaCl}_{2} \cdot 2 \mathrm{H}_{2} \mathrm{O}$ ) was used, with $5 \mathrm{~g} / \mathrm{L} \mathrm{NaHCO}_{3}$ by alkaline buffer. Iodoform (15 ppm) was used as a methane inhibitor [18,21]. To the fermentation medium, $50 \mu \mathrm{L}$ of both DSMZ 320 trace element solution and DSMZ medium 503 vitamin solution was added. The total volume of each culture was brought to $100 \mathrm{~mL}$ in a $250 \mathrm{~mL}$ flask. Fermentation was conducted in a shaking incubator with $250 \mathrm{~mL}$ flasks that were sealed with silicon rubber stoppers, after which anaerobic digestion proceeded for 2 weeks.

\subsection{VFA Concentration Analysis}

VFA samples from the anaerobic digestion were analyzed by HPLC using an Aminex HPX-87H column (Bio-Rad Laboratories, Hercules, CA, USA) with a refractive index (RI) detector. Mobile phase was $5 \mathrm{mM}$ of $\mathrm{H}_{2} \mathrm{SO}_{4}$ at a $0.6 \mathrm{~mL} / \mathrm{min}$ flow rate and temperature was $65^{\circ} \mathrm{C}$. Before HPLC analysis, all samples were filtered through a $0.22 \mu \mathrm{m}$ PVDF filter.

\subsection{Central Composite in Cube in Design and Selection of Variables}

A central composite (CCD) design for two independent variables was used for approaching the optimum settings. The CCD design, which consists of $2^{2}$ factorial design augmented by a center $(n=3)$, along with $2 \times 2$ axial points, was employed in this study with a slight modification. The concentrations of VFAs, including acetic, propionic, and butyric acids were determined at each CCD point. As shown in Table 3, $\mathrm{pH}\left(\mathrm{X}_{1}\right)$ and inoculation $\left(\mathrm{X}_{2}\right)$ were chosen as the two independent factors in the experimental design. The central values of the experiment design were selected as $\mathrm{pH} 9$ and $25 \%(v / v)$ inoculation at mesophilic $\left(35^{\circ} \mathrm{C}\right)$ temperature. Regression analyses were performed using experimental data. To optimize and analyze the factors that affected the total concentration of VFAs, including acetic, propionic, and butyric acid, in the acidogenic stage, RSM was applied. A test of the validity of the model was used to estimate polynomials (Equation (4)) [26].

$$
\eta_{\mathrm{a}}=c_{\mathrm{o}}+\sum_{i=1}^{n} \alpha_{i} x_{i}+\sum_{i=1}^{n} \alpha_{i i} x_{i}^{2}+\sum_{i} \sum_{j} \alpha_{i j} x_{i} x_{j}
$$

where $\eta_{\mathrm{a}}$ : the experimental value of a ( $\mathrm{a}=$ VFAs concentration); $x_{k}$ : independent variable $k$ ( $k=$ initial $\mathrm{pH}$ and inoculation in that order); $c_{\mathrm{o}}$ : regression constant; $\alpha_{k}$ : regression coefficients of the independent variable $k$ ( $k=$ initial $\mathrm{pH}$ and inoculation in that order).

Table 3. Data for independent variables and their levels used in the experimental design.

\begin{tabular}{cccc}
\hline \multirow{2}{*}{ Factor } & \multicolumn{3}{c}{ Coded Levels } \\
\cline { 2 - 4 } & $\mathbf{- 1}$ & $\mathbf{0}$ & $\mathbf{1}$ \\
\hline $\mathrm{pH}, \mathrm{X}_{1}$ & 6.5 & 9.0 & 11.5 \\
Inoculation $(\%), \mathrm{X}_{2}$ & 5 & 25 & 45 \\
\hline
\end{tabular}


The least-squares method was used to estimate the parameters in the approximating polynomials. A pH range between 6.5 and 8.5 was selected for the first experiment. Subsequently, the optimum point was determined to be a boundary condition; therefore, the $\mathrm{pH}$ condition was changed from 6.5 to 11.5. (Table 3). Eleven trials were performed to approximate the response.

\section{Conclusions}

Bioenergy and biofuel are advantageous for reducing greenhouse gas emissions and carbon neutrality. However, their widespread utilization is hindered by economical limitations, particularly the feedstock cost. We studied microbial lipids suitable for conversion into biodiesel and additional lipid production from yeast-residue VFAs after lipid extraction. The VFA production was optimized using an inoculation ratio of $39.49 \%$ and an initial $\mathrm{pH}$ of 8.4, which yielded $0.458 \mathrm{~g}$ VFAs/g LEY residue. Cell residue recycling increased the lipid yield from the substrate by $28.9 \%$. However, additional process costs include extraction, anaerobic digestion, and yeast cultivation during recycling. Hence, microbial lipid production from LEY increases the total lipid production, but recycling requires additional process costs. Therefore, the LEY recycling frequency should be carefully considered to make the approach feasible.

Supplementary Materials: The following are available online at https:/ /www.mdpi.com/article/10 $.3390 /$ catal11081009/s1, Figure S1: Growth curve and accumulation of lipids during incubation of C. curvatus for $72 \mathrm{~h}$.

Author Contributions: Conceptualization, G.W.P. and S.S. (Seongsoo Son); methodology, M.M. and S.S. (Seongsoo Son).; software, S.S. (Seongsoo Son) and K.M.; formal analysis, M.M. and S.S. (Subin Sin); writing - original draft preparation, G.W.P., K.M. and H.N.C.; writing—review and editing, G.W.P., J.-S.L. and H.N.C.; funding acquisition, M.M. and J.-S.L. All authors have read and agreed to the published version of the manuscript.

Funding: This research was supported by the National Research Foundation of Korea (NRF) grant funded by the Korea government (MSIT) (No. 2021R1A5A1028138) and C1 Gas Refinery Program through the National Research Foundation of Korea (NRF) funded by the Ministry of Science and ICT (2021M3D3A1A01079479).

Conflicts of Interest: The authors declare no conflict of interest.

\section{References}

1. Papanikolaou, S.; Aggelis, G. Lipids of oleaginous yeasts. Part I: Biochemistry of single cell oil production. Eur. J. Lipid Sci. Technol. 2011, 113, 1031-1051. [CrossRef]

2. Wynn, J.; Ratledge, C. The biochemistry and molecular biology of lipid accumulation in oleaginous microorganisms. Adv. Appl. Microbiol. 2002, 51, 1-51.

3. Fakas, S.; Papanikolaou, S.; Galiotou-Panayotou, M.; Komaitis, M.; Aggelis, G. Organic nitrogen of tomato waste hydrolysate enhances glucose uptake and lipid accumulation in Cunninghamella echinulata. J. Appl. Microbiol. 2008, 105, 1062-1070. [CrossRef]

4. Papanikolaou, S.; Aggelis, G. Yarrowia lipolytica: A model microorganism used for the production of tailor-made lipids. Eur. J. Lipid Sci. Technol. 2010, 112, 639-654. [CrossRef]

5. FAO. The State of Food and Agriculture, Biofuels: Prospects, Risks and Opportunities; Food and Agriculture Organization of the United Nations: Rome, Italy, 2008.

6. Chisti, Y. Biodiesel from microalgae. Biotechnol. Adv. 2007, 25, 294-306. [CrossRef]

7. Fei, Q.; Chang, H.N.; Shang, L.; Choi, J.-D.-R. Exploring low-cost carbon sources for microbial lipids production by fed-batch cultivation of Cryptococcus albidus. Biotechnol. Bioprocess Eng. 2011, 16, 482-487. [CrossRef]

8. Sathiyamoorthi, E.; Kumar, P.; Kim, B.S. Lipid production by Cryptococcus albidus using biowastes hydrolysed by indigenous microbes. Bioprocess Biosyst. Eng. 2019, 42, 687-696. [CrossRef]

9. Park, G.W.; Fei, Q.; Jung, K.; Chang, H.N.; Kim, Y.-C.; Kim, N.j.; Choi, J.d.R.; Kim, S.; Cho, J. Volatile fatty acids derived from waste organics provide an economical carbon source for microbial lipids/biodiesel production. Biotechnol. J. 2014, 9, 1536-1546. [CrossRef]

10. Huang, X.; Chen, R.; Yuan, M.; Liu, J. Efficient bioconversion of high-content volatile fatty acids into microbial lipids by Cryptococcus curvatus ATCC 20509. Bioresour. Technol. 2017, 239, 394-401. 
11. Liu, J.; Yuan, M.; Liu, J.-N.; Huang, X.-F. Bioconversion of mixed volatile fatty acids into microbial lipids by Cryptococcus curvatus ATCC 20509. Bioresour. Technol. 2017, 241, 645-651. [CrossRef]

12. Park, G.W.; Chang, H.N.; Jung, K.; Seo, C.; Kim, Y.-C.; Choi, J.H.; Woo, H.C.; Hwang, I.-J. Production of microbial lipid by Cryptococcus curvatus on rice straw hydrolysates. Process. Biochem. 2017, 56, 147-153. [CrossRef]

13. Fontanille, P.; Kumar, V.; Christophe, G.; Nouaille, R.; Larroche, C. Bioconversion of volatile fatty acids into lipids by the oleaginous yeast Yarrowia lipolytica. Bioresour. Technol. 2012, 114, 443-449. [CrossRef] [PubMed]

14. Llamas, M.; Tomás-Pejó, E.; González-Fernández, C. Volatile Fatty Acids from Organic Wastes as Novel Low-cost carbon source for Yarrowia lipolytica. New Biotechnol. 2020, 56, 123-129. [CrossRef]

15. Huang, X.-F.; Liu, J.-N.; Lu, L.-J.; Peng, K.-M.; Yang, G.-X.; Liu, J. Culture strategies for lipid production using acetic acid as sole carbon source by Rhodosporidium toruloides. Bioresour. Technol. 2016, 206, 141-149. [CrossRef] [PubMed]

16. Fei, Q.; O’Brien, M.; Nelson, R.; Chen, X.; Lowell, A.; Dowe, N. Enhanced lipid production by Rhodosporidium toruloides using different fed-batch feeding strategies with lignocellulosic hydrolysate as the sole carbon source. Biotechnol. Biofuels 2016, 9, 130. [CrossRef]

17. Chang, H.N.; Kim, N.-J.; Kang, J.; Jeong, C.M. Biomass-derived volatile fatty acid platform for fuels and chemicals. Biotechnol. Bioprocess Eng. 2010, 15, 1-10. [CrossRef]

18. Park, G.W.; Seo, C.; Jung, K.; Chang, H.N.; Kim, W.; Kim, Y.-C. A comprehensive study on volatile fatty acids production from rice straw coupled with microbial community analysis. Bioprocess Biosyst. Eng. 2015, 38, 1157-1166. [CrossRef]

19. Zheng, Y.; Chi, Z.; Ahring, B.K.; Chen, S. Oleaginous yeast Cryptococcus curvatus for biofuel production: Ammonia's effect. Biomass Bioenergy 2012, 37, 114-121. [CrossRef]

20. Sri Bala Kameswari, K.; Chitra, K.; Porselvam, S.; Thanasekaran, K. Optimization of inoculum to substrate ratio for bio-energy generation in co-digestion of tannery solid wastes. Clean Technol. Environ. Policy 2011, 14, 241-250. [CrossRef]

21. Pham, T.N.; Nam, W.J.; Jeon, Y.J.; Yoon, H.H. Volatile fatty acids production from marine macroalgae by anaerobic fermentation. Bioresour. Technol. 2012, 124, 500-503. [CrossRef]

22. Pan, J.; Zhang, R.; Elmashad, H.; Sun, H.; Ying, Y. Effect of food to microorganism ratio on biohydrogen production from food waste via anaerobic fermentation. Int. J. Hydrogen Energy 2008, 33, 6968-6975. [CrossRef]

23. Gebremariam, S.; Marchetti, J.M. Economics of biodiesel production. Energy Convers. Manag. 2018, 168, 74-84. [CrossRef]

24. Meesters, P.; Huijberts, G.; Eggink, G. High-cell-density cultivation of the lipid accumulating yeast Cryptococcus curvatus using glycerol as a carbon source. Appl. Microbiol. Biotechnol. 1996, 45, 575-579. [CrossRef]

25. Folch, J.; Lees, M.; Sloane-Stanley, G. A simple method for the isolation and purification of total lipids from animal tissues. J. Biol. Chem. 1957, 226, 497-509. [CrossRef]

26. Yang, K.; Oh, C.; Hwang, S. Optimizing volatile fatty acid production in partial acidogenesis of swine wastewater. Water Sci. Technol. 2004, 50, 169-176. [CrossRef] [PubMed] 